\title{
Using site-specific nitrogen management in rainfed corn to reduce the risk of nitrate leaching
}

\author{
Maria del Pilar Muschietti-Piana ${ }^{\mathrm{a}, \mathrm{b}}$, Pablo Ariel Cipriotti ${ }^{\mathrm{c}}$, Susana Urricariet ${ }^{\mathrm{b}}$, Nahuel Raul \\ Peralta $^{\mathrm{d}}$, Mauricio Niborski ${ }^{\mathrm{b}}$ \\ ${ }^{\text {a }}$ Department of Natural Resources and Environment, School of Agriculture, Universidad de \\ Buenos Aires, C1417DSE BA, Argentina \\ ${ }^{\mathrm{b}}$ Department of Land Use and Agriculture, School of Agriculture, Universidad de Buenos Aires, \\ C1417DSE BA, Argentina \\ ${ }^{\mathrm{c}}$ Department of Quantitative Methods and Information Systems, School of Agriculture - IFEVA, \\ Universidad de Buenos Aires/CONICET, C1417DSE BA,Argentina \\ ${ }^{\mathrm{d}}$ Department of Market and Development of Corn, BAYER Crop Science. Ruta 8, Fontezuela, \\ Pergamino, Argentina
}

Keywords: Management zones, Yield potential, Soil residual-nitrogen, Water use efficiency, Drought, Nitrogen use efficiency

\begin{abstract}
Managing nitrogen (N) to achieve yield potential and limit losses to the environment is challenging due to the temporal and spatial variability in crop $\mathrm{N}$ uptake which affects the distribution of soil-N. Nitrogen fertilization using site-specific management (SSM) is one of a number of strategies that can improve the efficiency of $\mathrm{N}$ use and reduce the losses of $\mathrm{N}$ to the environment from cropping systems. The aim was to assess: (i) corn (Zea mays L.) grain yield and $\mathrm{N}$ uptake; and (ii) soil residual- and potentially leachable-N, and its relationship with $\mathrm{N}$ and water use efficiency using SSM vs. uniform management (UM) strategies in high-(HP) and low-(LP) productivity zones on soils of the Inland Pampas of Argentina. Differences in soil residual- and potentially leachable-N, corn grain yield, $\mathrm{N}$ uptake, water and $\mathrm{N}$ use efficiency were compared between treatments. In HP-zones, corn grain yield and total biomass were 2.7 and $4.2 \mathrm{Mgha}^{-1}$ higher with SSM than UM, and corn grain $\mathrm{N}$ uptake and total $\mathrm{N}$ uptake increased by $21 \%$ and $18 \%$ with SSM when compared to UM. Soil residual-N at field-scale was reduced by $18 \%$ with SSM. Marginal differences in potentially leachable-N among treatments were observed throughout the soil profile; the highest nitrate concentration was $6.6 \mathrm{mg} \mathrm{kg}^{-1}$ in LPzones with UM within the $210-240 \mathrm{~cm}$ soil layer. Overall corn water use efficiency in total biomass was $16 \%$ higher with SSM than with UM in both LP- and HP-zones. Using SSM in the LP-zones increased corn N use efficiency in grain and total biomass by $50 \%$ and $43 \%$ respectively. In this context, SSM can be considered as a conservation practice that optimizes $\mathrm{N}$ and water use efficiency by corn under dry conditions.
\end{abstract}

Publicado originalmente en: Maria del Pilar Muschietti-Piana, Pablo Ariel Cipriotti, Susana Urricariet, Nahuel Raul Peralta, Mauricio Niborski. Using site-specific nitrogen management in rainfed corn to reduce the risk of nitrate leaching. Agricultural Water Management. 199: 61-70

DOI: https://doi.org/10.1016/j.agwat.2017.12.002 